\title{
Globalised Threads
}

\section{Costumes of the Hmong}

\section{Community in North Queensland}

\section{Maria Wronska-Friend}

here are very few societies in the world in which costume,
whether an everyday dress or festive garment, has received such significant cultural recognition as in the case of the Hmong people. Costumes and silver jewellery have become for the Hmong their major form of artistic expression, a means of visual communication as well as a marker of ethnic identity. The Hmong costume adorns and protects, but it also sends subliminal messages about its owner's gender, group membership, locality, marital status, wealth, and so on. This study is based on research conducted during 1995-2003 among Hmong communities in Innisfail and Cairns in north Queensland, as well as in Yunnan Province, China, in June 2000. ${ }^{1}$ The current situation of the Hmong costume in Australia will be analysed in terms of its manufacture, supply and use, as well as its function as a gift token, which connects the worldwide diaspora of Laotian Hmong migrants together.

Like all artefacts, Hmong costume should be perceived not only as a material construct but also as a manifestation of ideas and a means by which cultural categories and principles are encoded and expressed. Under the increasing impact of cultural 
globalisation, the analysis of Hmong costumes will assist us in understanding the social changes experienced by the Hmong at both a regional and a global level.

\section{The Hmong Community in North Queensland}

From the late 1970s to the early 1980s Australia accepted approximately 1,600 Laotian Hmong from refuge camps in Thailand. Initially, the major settlements of the Hmong population in Australia were in Tasmania, Sydney and Melbourne. From about 1996, north Queensland became the major centre of the Hmong population in the country, with more than 800 people representing 52 households and twelve clans in $2002 .^{2}$

Cairns became home to approximately 300 Hmong people, largely Green Hmong (Hmoob Ntsuab), ${ }^{3}$ while some 550 White Hmong (Hmoob Dawb) settled in the rural area of Innisfail, 100 kilometres to the south of Cairns. While the Hmong in Cairns earn a living by working usually as labourers in small industries and services, the Hmong in Innisfail work on banana plantations, which are usually run as family businesses. While many of the Hmong who live in Cairns have converted to Christianity, the majority of the Innisfail Hmong still follow their traditional system of belief, in which the shaman plays the important role of mediator, connecting the world of the living with the realm of spirits.

Migration and frequent changes in place of residence as a result of shifting cultivation have long been a well established tradition of the Hmong community. This aspect of the traditional Hmong lifestyle has continued to a certain extent even since their arrival in Australia. For a number of Hmong families, north Queensland is their second or even third place of residence in Australia, usually following initial settlement in Tasmania, Melbourne or Sydney. From about the year 2000, Brisbane started to gain significance as another place of Hmong residence, with several families moving there from north Queensland and other states.

It is most probable, however, that for a number of years north Queensland will remain the most favoured place for Hmong settlement in Australia. The local climate and vegetation are similar 


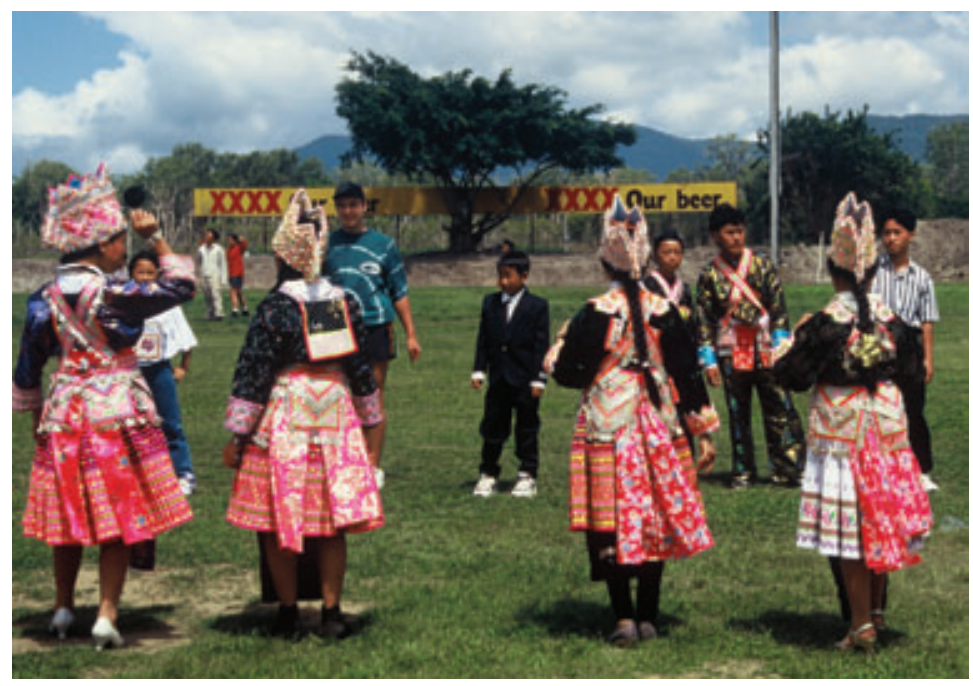

Tossing the ball (pov pob) is a courtship game, accompanying all New Year celebrations, Cairns.

to the environment they knew in Laos and allow similar food crops to be grown for family consumption. At the same time, involvement in farming in the area provides a number of practical as well as cultural benefits.

The Hmong have a strong work ethic and it is important for them to engage in meaningful, productive work, with all family members being involved. Work on banana plantations, most of which are owned by the Hmong, offers an opportunity of employment for almost all family members, notwithstanding their formal skills, qualifications or knowledge of English. In this respect, work on banana plantations is similar to subsistence farming in Laos, where every member of the family was involved in some form of meaningful work according to his or her skills and experience. The rate of unemployment among the north Queensland Hmong is very low.

Another advantage of work on farms and plantations is a much higher degree of cultural privacy than suburban life can provide. It is much easier to conduct certain cultural practices, 
especially healing or mortuary rituals which require the use of loud musical instruments or animal sacrifice, inside the sheds of remote banana plantations, than in the small suburban gardens of Melbourne or Sydney. Thus, the environment of north Queensland provides a significant degree of cultural autonomy that is vital for the community's well-being and allows a slow and controlled process of adjustment to the mainstream life of Australian society.

\section{In the Village and in the Refugee Camps: Hmong Costumes Prior to Arrival in Australia}

Evidence provided by older community members who had been brought up in villages in Laos during the 1950s and 1960s shows that in most cases the Hmong were traditionally self-sufficient in the production of everyday clothes. Hemp (maj), an important fibre of utilitarian as well as ritual significance, was commonly cultivated and processed. Natural indigo was the most frequently used dye, although there was increasing access to synthetic dyes. From about five years of age, all the girls were trained to make several types of elaborate embroidery and sewn garments - a skill which was seen as an important aspect of their female identity. Costume was an important marker of the group's image, and a code of dress which differed between each Hmong sub-group was strictly adhered to. It may have been these different types of costumes which resulted in distinctive names being given to the sub-groups of Hmong (Adams 1974, Bernatzik 1947).

In towns the situation was more relaxed, with many Hmong women wearing Lao sarongs, while the men often wore Western garments.

This situation drastically changed following the escape from Laos, in the aftermath of the Indochinese conflict of the 1970s, of thousands of Hmong who found temporary protection in the refugee camps of Thailand. Almost all the Hmong who fled from Laos spent several years in such refugee camps before emigrating to the West, and this powerful experience of displacement and social disruption had a major impact on their costume and textile art. 


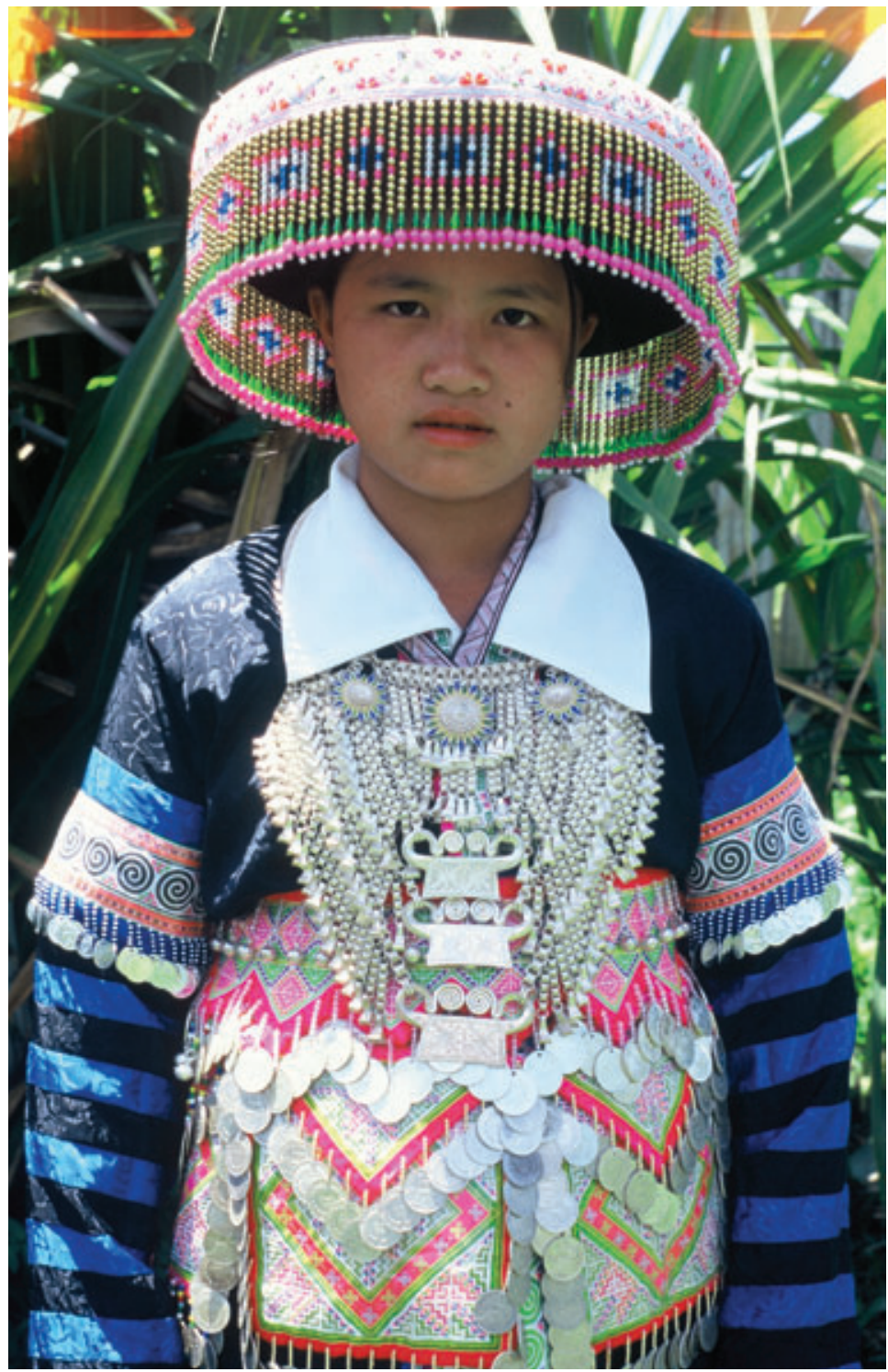

Hmoob Quas Npab - 'Striped' Hmong girl in a festive costume, the components of which originated in four countries (USA, China, Thailand and Australia), Innisfail. 
After 1975, following the major exodus of the Hmong from Laos, a chain of refugee camps was established along the Thai border. Some of them, such as Ban Vinai, which at times had to accommodate up to 50,000 refugees, became the largest gatherings of Hmong people in the world (Conquergood 1992).

Many older members of the Hmong community in north Queensland remembered that the escape from Laos had been a watershed in the processes of change in wearing everyday Hmong dress. As is shown in oral histories and photographs, traditional everyday Hmong costume was replaced either by Western dress or (for women) by a Thai sarong in the majority of refugee camps. Hmong dress, however, continued to be worn on special occasions such as the New Year, marriage ceremonies or funerals. In photographs representing the marriages which took place in refugee camps, usually both the bride and the groom wear traditional Hmong costumes. ${ }^{4}$

The refugees were able to bring only a limited amount of their personal possessions to Thailand, including costumes and jewellery. The dramatic escape from Laos, which involved walking for a number of days through the jungle and then secretly crossing the Mekong River by raft and boat, meant that the Hmong could carry little with them. Most of their treasured costumes and jewellery had to be abandoned or left in secret places in Laos. In some cases, silver jewellery was given to Lao fishermen as payment for the life-saving boat ride across the Mekong River. In other cases, Thai border guards confiscated objects of monetary value, such as jewellery (Mr Ly Lao, Innisfail, personal communication, 1995).

Despite these circumstances, some Hmong managed to bring small bundles of costumes which had special meanings for them into the refugee camps. For instance, Sai Xiong carried with him a jacket which he had embroidered himself - a very unusual task for a Hmong man (Mr Sai Xiong, Innisfail, personal communication, 2002). Jou Yang, on leaving her home, took with her a jacket and an apron which had been embroidered by her deceased mother. It accompanied her to Ban Vinai and was later taken to Australia. ${ }^{5}$

Only a few such Hmong costumes made in Laos survived the refugee camps of Thailand and were brought to Australia. 


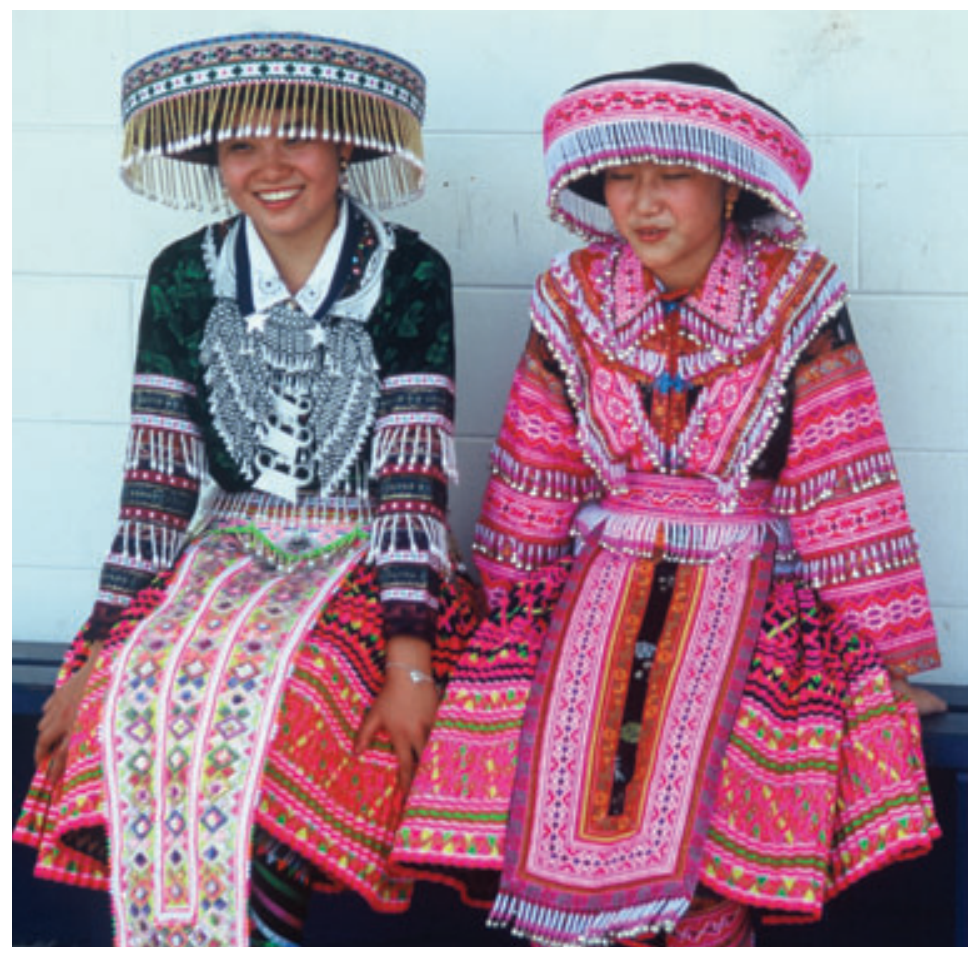

Hmong girls during New Year celebrations. The pink costume was imported fom China; the other costume represents new, composite type of Hmong costume, Cairns.

Those that did became highly treasured mementoes of life in Laos, attaining the status of heritage objects, too precious to be worn. In some refugee camps, there were instances of limited trade in traditional costume with Hmong living in Thailand. For instance, Jou Yang, on her marriage in 1981 in Ban Vinai refugee camp, received from her aunt a white pleated skirt made of eight metres of hemp fabric. The skirt was made by the White Hmong who live in Thailand. Jou has never worn this skirt and never will - she keeps it as a treasure, as 'a very special Hmong thing'. On the day of her funeral the skirt will be deposited in her coffin (Mrs Jou Yang, Innisfail, personal communication, 2002).

Silver jewellery, which in Laos and other Southeast Asian countries was used by the Hmong as a store of wealth, was replaced 
in the refugee camps by items of identical form but made of aluminium. These were frequently made from recycled tins in which food rations had been served (Mr Ly Lao, Innisfail, personal communication, 1995).

The abundance of time and the necessity to generate income in the refugee camps resulted in the creation of a new genre of commercialised textile art destined for the outside market. Under the guidance of craft advisers, new textile forms were created and produced in thousands of copies. These included pillow covers, table runners, wall hangings and various types of small decorative fabrics. Some of these were decorated with traditional designs copied from older Hmong garments and executed in reverse appliqué or crossstitch. However, as most of these textiles were destined for the Western market, in which the symbolic language of the traditional Hmong designs was unintelligible, the Hmong changed the decorative style of their textiles from abstract, geometrical designs into realistic narrative representations which could easily be understood by outsiders. Most remarkable of these were the large pictorial representations of everyday life scenes remembered from Hmong villages in Laos, illustrations of ancient legends and myths of creation or, probably best known, graphic scenes representing the cruelty and trauma experienced during the war in Laos or during the escape to Thailand (Bessac 1988, Cohen 1990, Conquergood 1992).

It is probable that the motivation for the execution of these monumental fabrics was not only the commercial need for income, but also that their creation became a form of catharsis, providing relief from memories of war atrocities experienced in Laos and a way to expose the cruelties they suffered to the outside world. Catering to the Hmong demand for textiles, shops were established on the outskirts of the camps which sold the fabrics and accessories required to create Hmong costumes. In several cases, families who were accepted for migration to Australia bought, prior to their departure, expensive fabrics such as black shiny synthetic cloth (an upmarket version of the humble black cotton used to make everyday Hmong dress) from which new costumes were made to celebrate their arrival in a new country. Doua Yang, on his arrival in Hobart in 1987, took a photograph to commemorate this important event in the life of his family: both he and his wife wear 


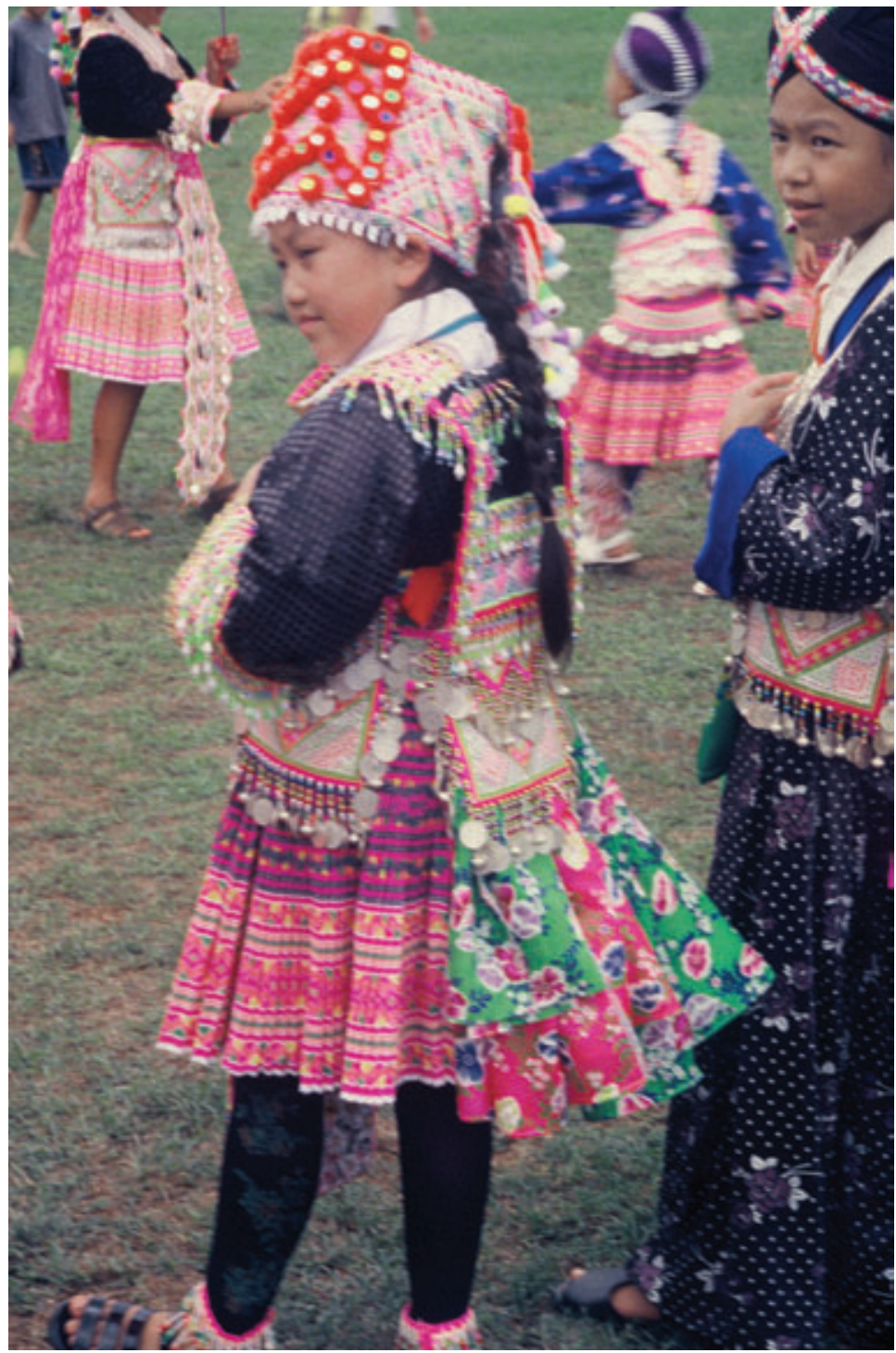

New year celebrations in Innisfail. The components of the costume are gifts, sent by relatives in overseas countries. 
new costumes, made of black synthetic cloth purchased especially for this occasion from a shop outside Ban Vinai camp (Mr Doua Yang, Innisfail, personal communication, 2002).

\section{Textile Art on Arrival in Australia}

After their arrival in Australia, from the late 1970s to the early 1980s, the textile traditions of the Hmong underwent still further transformations, which reflected the very new social situation in which the group now found itself.

The very successful commercial production of Hmong textiles, which had flourished in the refugee camps in Thailand, has almost disappeared in Australia. Faced with new responsibilities and commitments, Hmong women, especially those employed in the horticultural industry, who had to look after their extended families, found that the pressures and demands of everyday life left little time to engage in the production of these elaborate and frequently monumental embroideries. Another factor contributing to the decline of this activity was the lack of assistance from external agencies in the distribution and marketing of the clothes. Some of the older, unemployed, Hmong women said that they would have been prepared to make commercial embroidery for sale, but were unable to get any support for the regular distribution and retail marketing of their products. Although in the 1980s Hmong embroidered cloths were occasionally sold from market stalls in Hobart, Melbourne and Sydney, the profit generated in this way was an additional source of income, not the primary source it had been in the refugee camps. Most of the embroidered pieces sold in this way were brought from Thailand as part of the migrants' luggage, or sent to Australia by family members who still remained in the refugee camps. A proportion of the profits was returned to relatives in Thailand (Mr Ly Lao, Innisfail, personal communication, 1995).

The case of the large embroidery piece representing the atrocities of the war in Laos which Mrs Poyi Thao of Cairns started to produce in 1986 in Ban Vinai refugee camp illustrates the difficulties experienced in textile production in Australia. The cloth was only completed in Australia ten years after her arrival in 


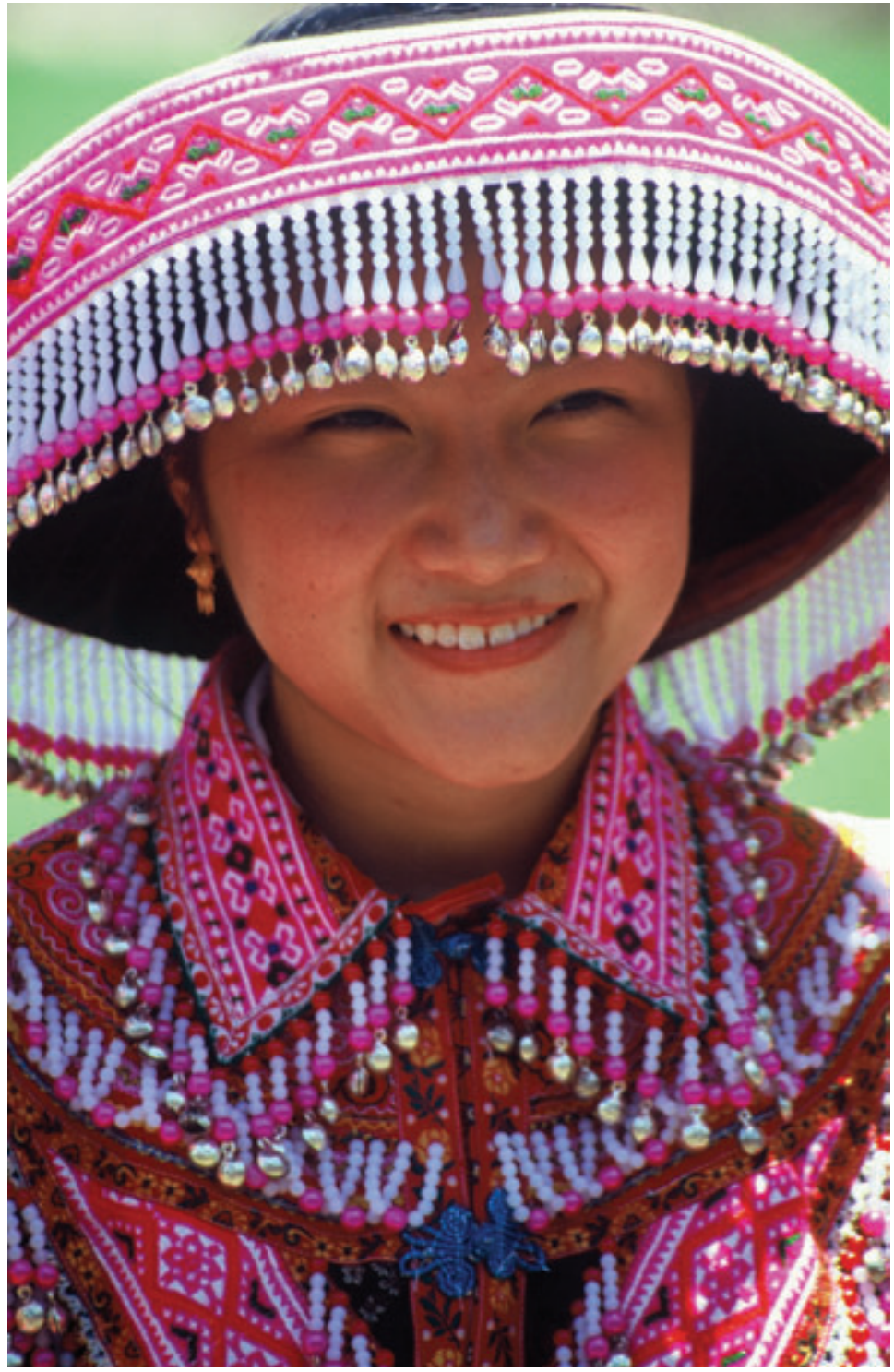

Hmong girl attending New Year celebrations in Cairns, in costume imported from China. 
the country, in order to be presented at the Hmong textile art exhibition 'Migrants from the Mountains' organised by James Cook University in Townsville (in spite of the organisers' suggestions, Poyi Thao did not wish to display an uncompleted fabric). The reason she gave for the delay in completing this embroidery was the unsettled and busy lifestyle of the new country which was, she said, not conducive to the undertaking of such monumental projects, requiring so much time and concentration. ${ }^{6}$

The custom of wearing everyday Hmong costume, then, had in most cases already ceased to exist prior to the arrival of the Hmong in Australia, and it has not been revived in this country. The only part of the traditional Hmong costume which is still used in Australia in everyday situations is the baby carrier. Its continued use is due, no doubt, to its practicality: it provides the mother with freedom of movement and the opportunity to perform other tasks, while knowing that the baby is safe. Baby carriers are frequently sent as gifts by mothers and mothers-in-law to their expecting daughters and daughters-in-law, especially when a first baby is due. Mai Yang, who lives in Innisfail, has received nine baby carriers as gifts from her mother, who lives in France: each of them signalled the birth of a new baby. While some of the baby carriers were fully executed by her mother, others were made by Hmong refugees in Thailand, sent to France where the mother provided the 'finishing touches', and then forwarded to Australia (Mrs Mai Young, Innisfail, personal communication, 2002). I expand on the significance of these kinds of composite productions below.

Although in Australia the everyday Hmong costume has generally lost its meaning as a visual marker of Hmong identity, there has been one exception to this rule. In 1999, four Hmong families moved away from the mainstream Hmong communities of Cairns and Innisfail and settled inland, on the highlands of the Atherton Tablelands. The group started to use the name 'Amu' and established a new religious identity. The Amu believe that they are connections to the mythical Hmong emperor and have developed a distinctive set of rules and traditions to support this claim, including construction of a monumental temple. As an identifying mark, the members of this group wear in everyday situations either 
a full set of Hmong costume or at least parts of it - such as jackets, skirts or caps decorated with traditional Hmong designs (Mr Ly Lao, personal communication, 2002-2003).

The reaction of the mainstream north Queensland Hmong community members towards the Amu costumes is negative. Wearing an ethnic costume as everyday dress and trying to differentiate themselves from mainstream Australian society is considered to be an extravagant and unnecessary practice. According to the common opinion, the use of the Hmong costume is well justified on celebratory, festive occasions - but not any longer in everyday situations, where it is important to comply with the image projected by the dominant group.

\section{Textile Production in Australia: Lost Skills and Gained Experience}

Only some out of the diverse range of textile decorative techniques used by the Hmong in Laos continue to be practiced in Australia, and in most cases this is to satisfy immediate personal and family needs. Neither weaving nor dyeing of textiles is continued in Australia. Unlike in the United States, none of the Hmong in Australia make the batik cloth (wax-resist technique) from which the Green Hmong women's skirts are made (John Michael Kohler Arts Centre 1986). As a consequence, all the indigo-dyed skirts worn by Hmong Ntsuab women in Australia have to be imported from overseas - usually from Laos, Thailand, China or the United States. In many cases, industrial printed cloths imitating batik designs have replaced the fine, hand-drawn wax ornamentation. There is a somewhat different situation as regards the white, pleated skirts which are a distinctive part of the White Hmong women's costume. In Australia there are two women who used to make these skirts: Chi Lee of Innisfail, and another Hmong woman who lives in Sydney. The former, being an invalid for part of her life, was unable to work on the family banana farm and therefore had the time to be involved in the production of such elaborate garments. She learned the skill as a young woman in 
Laos, as in her village all garments were produced at home. In Australia, she has made skirts in the same way, although white cotton has now replaced the traditionally used undyed hemp: all the skirts are carefully pleated and hand-stitched from nine to twelve metres of white cotton cloth, purchased from shops in Cairns. During the 23 years of her life in Australia, Chi Lee has produced about 200 white skirts, which she sold or gave away to family members. Now she is in her 70 s, and poor eyesight has prevented her from making any more skirts. There were attempts to find a group of younger Hmong women to whom she could pass on this skill, but nobody expressed very much interest (Mrs Chi Lee, Innisfail, personal communication, 2003).

As regards embroidery produced for family needs, crossstitch and reverse appliqué still remain two of the most popular techniques, practiced by older and middle-aged women. Reverse appliqué, practiced exclusively by White Hmong women, and which requires a very high degree of skill and patience, has been transmitted to a very small group of women in the younger generation. It has been largely replaced by cross-stitch which, even in its finest form, is much faster and an easier needlework method than reverse appliqué. Therefore cross-stitch patterns, frequently covered with protective sheets of plastic, dominate the decoration of festive Hmong costumes in Australia. The excessive amount of time and prolonged concentration required when producing reverse appliqué have been given as the reasons for its demise and the increased popularity of cross-stitch embroidery.

In Laos, needlework used to be the domain of women and an important characteristic defining Hmong womanhood. During New Year celebrations, young women used to be judged on their needlework skills, as careful handiwork used to signal an industrious, hard-working wife to a future husband. However, in Australia, a different set of values is used in creating a positive image of the Hmong woman and a different set of criteria is used in selecting a future wife. In public situations, young Hmong women still like to wear bright, eye-catching attractive costumes - but only in exceptional situations are they the authors of their own decorations. 
Hundreds of hours spent on the painstaking execution of elaborate designs have little or no relevance to the lifestyle of the younger generation of Hmong women in Australia. Therefore it is quite difficult to motivate young women to learn these skills. In 2002, the Hmong association in Cairns, known as the Federation of Hmong National Culture, received a grant of $\$ 2,700$ from the Multicultural Affairs Department office in Queensland to teach young women traditional embroidery skills. Whether this project will have any long-lasting effects, however, remains to be seen.

\section{Costumes of Many Lands: Australian Hmong Festive Garments}

In spite of the demise of traditional Hmong costume worn as an everyday garment, it continues to play a very important role in the social life of the community as a festive dress. It acts as an important marker of ethnic identity, worn only three or four times during the year, on occasions such as family and community celebrations, especially during the Hmong New Year festivals and at welcoming or farewell ceremonies when a group of Hmong relatives or friends moves to another place. Of especial importance continue to be the New Year celebrations, when every member of the family wears a new set of clothes, usually richly decorated with embroidered paj ntauj panels. This old tradition of wearing bright, new clothes for such occasions continues to be upheld in Australia. This is to ensure prosperity for the coming year, and bring wealth and success.

The Hmong wear their traditional costume not only at events celebrated within their own community, but also when they wish to express their ethnic identity in regard to the rest of Australian society - such as at local cultural festivals, Australia Day, or when invited to attend events staged by other north Queensland migrant groups, such as the Buddhist New Year celebrated by Lao and Thai people.

As I have already mentioned, local production of Hmong garments and embroidered cloths is limited. The majority of the 
costumes worn on these occasions, therefore, have either been received as gifts from relatives living abroad or assembled in Australia from decorative elements produced overseas. An analysis of the origins of the components of several contemporary Hmong costumes worn in Australia reveals an extensive network of international connections established between the Australian Hmong and the rest of the Hmong diaspora. In outline, there are three major sources providing a supply of Australian Hmong costumes and their accessories.

\section{Costumes as Gifts Received from Relatives}

These gifts usually originate from relatives - members of the post-war Hmong diaspora, who have been dispersed to several parts of the globe. North Queensland Hmong have particularly close ties with family members who have migrated to the United States, France and Canada. They frequently visit each other and to commemorate these event, gifts made of fabrics, embroidered costume panels (paj ntauj), costume accessories (beads, silver coins), hats as well as full sets of garments are exchanged.

Light and portable, these costumes and their accessories function very well as tokens of memory and respect. Gift exchange of such items is a vital factor in building and strengthening the links between family members who settled in different parts of the world. In recent years, as a result of increased contacts with Laos, a growing number of costume components have originated from that country.

\section{Commercial Products Manufactured in Thailand or Laos}

The Hmong refugees from Laos who have remained in Thailand, estimated at approximately 10,000 people and concentrated largely around Tam Krabok temple in Saraburi province, have developed an impressive textile industry producing hand-embroidered accessories and full suits of Hmong festive costume. This production should be recognised as a continuation of the commercial tradition of the textile industry set up in the camps of Ban Vinai and Nam Yao during the 1970s and 1980s. However, the currently made textiles and costumes are destined almost exclusively for the Hmong migrant community, unlike the previous form of production which was targeted at Western markets. 
Once again, the production of these textiles has proved to be an important source of income for the remaining Hmong refugees in Thailand, who receive very limited external support.

The most frequently produced articles are sets of finely embroidered matching panels which are stitched onto the apron and jacket (along the front opening, sleeves and collar). The blue-dyed pleated skirt, either decorated with batik or printed with designs imitating batik, is another popular article. Finally, a range of richly decorated hats are also produced for Hmong clients living overseas.

The commercial production of Hmong embroideries in Laos, although smaller in scale, is very similar to that in Thailand. These products are usually purchased during visits to Thailand and Laos and, on return to Australia, sold to local community members. Sometimes mail-order purchases are organised.

\section{Industrial Hmong Costumes Produced in China}

In the 1990s a significant textile industry was developed in the Wenshan area in the southern part of Yunnan Province in China, specialising in the commercial mass production of costumes for Hmong migrants who had settled outside Asia. Unlike the handmade, commercialised embroideries produced in Thailand and Laos, these costumes are usually machine-made (including printed textiles and machine-made embroidery). Frequently the garments are made of synthetic fabric instead of cotton. The costumes are produced in bright colours ('shocking pink' being most frequently used) and decorated with strings of hanging beads. They are usually ordered from China and sold in Australia for $\$ 250$ to $\$ 300$ dollars each. This type of dress is particularly popular with young unmarried Hmong teenage girls.

In Australia, materials and parts of garments, many of which would be gifts sent by relatives, are freely combined with commercially produced or self-made costume components. An analysis of the origins of the basic components used in one costume, such as its fabrics, embroidered panels, beads, coins, hats or other accessories, can often identify several countries of ultimate origin, such as the United States, Canada, France, Laos or Thailand, reflecting the multitude of countries in which the members of one family may live. 
In one such example, an analysis of the origins of the individual parts of a Green Hmong costume worn by Mai Yang of Innisfail during the 2002 New Year celebrations shows how widely some of the Hmong families have been dispersed, following their escape from Laos.

Mai Yang's family had been sent from the refugee camps of Thailand to three different countries: her three sisters had migrated to the United States, while her parents and four other siblings moved to France. She followed her husband to settle in Australia. The blue, indigo-dyed skirt of her New Year costume was a commercial product, made by Hmong refugees in Thailand. From there, it was sent to Mai Yang's mother in France, who enhanced it with additional embroidery and presented it to her daughter during her visit to Australia. The mother also made the hat as well as embroidering the panels of the jacket. The pink fabric of the sash had originated in Mexico, from where it was sent to Mai Yang's sister who lives in California, and then on to Australia. The panels of cross-stitch embroidery which decorated the sash were produced by Mai Yang herself in Innisfail, while the silver coins and beads had originated from Thailand.

The costume of her husband, Pa Chao Thao, revealed a similar diversity of provenance: the garment was sent to him from France in 2002, as a gift for the forthcoming New Year celebrations. His mother-in law (who lives in France) created an elaborate embroidery in the latest fashion of intersecting star figures. The fabric for this costume, a dense velvet, was of Mexican origin and had been sent to France by one of her daughters who had migrated to the United States. In this way, the fabric and the costume circulated half the globe - from Mexico to California, and then to France and to Innisfail in Australia, each time creating new meanings and establishing new links between subsequent groups of Hmong givers and receivers (Mrs Mai Yang and $\mathrm{Mr} \mathrm{Pa}$ Chao Thao, Innisfail, personal communication, 2002).

A similar case of intricate global connections was revealed by parts of the festive costume worn by Sua Xiong. Although she had sewn the basic costume herself, some of its other parts and decorative elements were purchased or obtained from the United 
States and Laos where most of her family lives. For example, the apron was a gift from her husband's relatives in California. One of the sashes was a gift from her sister who also lives in the United States, while she had purchased another one in Laos when revisiting her home area of Luang Prabang. The commercial fabric with floral designs which was used as a lining for the cuffs had been made in Japan, then exported to the United States, where her sister had purchased it, and subsequently sent to Australia (Mrs Sua Xiong, Innisfail, personal communication, 2002).

Today, it is quite rare to find festive Hmong costumes produced in only one country. In most cases, the contemporary costumes worn by the Hmong in Australia provide tangible evidence of the widespread network of kinship connections developed by the Hmong who settled in several parts of the world during the last decades of the twentieth century. Costumes and their accessories thus act as important agents in the process of binding the Hmong diaspora together and strengthening their international linkages.

\section{New Costumes and New Meanings}

Hmong costumes, even in villages in Laos, have never been an inert, static entity - quite the opposite, they always used to be dynamic constructs, ready to include new materials and designs, influenced by the vagaries of local fashion as well as encoding the collective vision of the community.

In the new social context of Australia, the cultural meaning and significance of the costumes have undergone major changes, reflecting shifts in the social identity of the group. The fact that contemporary Hmong costumes and their constituent parts originate from so many different countries of the world, illustrates the dynamics of these changes and has contributed to the creation of the frequently hybrid and heterogeneous forms of these garments. Both the form as well as the function of the Hmong costume in Australia have been significantly transformed. 


\section{Costume as an Expression of a General Hmong Identity}

There is a growing tendency to use the costume as a means of expressing Hmong identity in general terms only, rather than identifying its owner as a member of one of the many Hmong subgroups, as is still the case in the Asian homelands of the Hmong. For instance, in China, Thailand or Laos one can still identify a member of the Hmong community on the basis of the costume the person wears; the garment is not only an aesthetic creation and a testimony to the skills of its maker, but also serves as an external sign of a person's sub-group identity (Geddes 1976). In this way, it is easy to distinguish White Hmong from Green Hmong on the basis of the colour of women's skirts as well as the type of collar attached to their jackets, or the different cut of the trousers worn by men. In Australia, this very elaborate, complex language of visual communication has become greatly simplified, and with every passing year is understood by fewer people. The intricacies of the symbolic system of communication have become largely unintelligible to the younger generation of Hmong, those who experienced the devastating cultural shock of the refugee camps or who were brought up in Australia. The designs, the colours and the special cuts of the garments are rapidly losing their semiotic meanings. Thus, in Australia, the Hmong costume in many cases has ceased to indicate the sub-group identity of its wearer. As such, its informative function has been greatly diminished. The message it sends is one of being a member of the Hmong community in the most general terms.

As one of the Australian Hmong teenagers stated:

I am a White Hmong, but apart from having a White Hmong costume, I also have a Green Hmong costume and a Chinese Hmong costume. In Australia, I can wear whatever I want (Melanie Lee, Innisfail, personal communication, 2001).

This statement is borne out to such an extent that in recent years several young Hmong women have started to wear Lao sarongs, made of lavish brocade fabrics, at the Hmong New Year celebrations. The preference for this type of costume has been 
influenced by idealised images of the Australian woman; the girls feel they look slimmer in sarongs than wearing the generously pleated Hmong skirts, while the brocade fabrics of the sarongs are shinier and look more lavish. After all, although it is not Hmong, this costume still originates from Laos.

\section{Creation of a Composite Costume}

In this situation, where the costume is in the process of losing much of its significance as a specific visual marker, the next stage is the deconstruction of the Hmong traditional costume and the creation of a new eclectic dress, composed of elements which traditionally were characteristic of several different Hmong costumes. This process of creating new composite costumes is especially common among the youngest generation of Hmong women, born and brought up in Australia, who in most cases are completely unaware of the complex visual language of the Hmong costumes worn in Laos. Varying components of several types of Hmong costumes are now grouped together in novel combinations. For instance, an indigo-dyed Green Hmong skirt may be combined with a White Hmong jacket and a round hat reminiscent of traditional turbans worn by the 'Striped' Hmong in Laos (Hmoob Quas Npab) and some groups of Chinese Hmong. The rules regarding the grouping of elements from various costumes into novel combinations are quite flexible. Strong visual impact of the dress, brightness of colour and richness of ornamentation seem to be the major criteria applied by the Hmong in creating their new ethnic apparel. Individual creativity expressed through this process is highly regarded. In many cases, one may observe a decisive shift from group expression towards individual creation in the forms of these new garments.

\section{Hmong Chinese (Hmoob Suav) Costume}

The third tendency characteristic of the transformation of Hmong costumes in Australia is the growing recognition of cultural connections with Hmong living in China, a country which is remembered as the original homeland of all the Hmong people. The relative affluence achieved by the Australian Hmong has allowed some members of the community to travel to China, 
visiting Hmong communities in Yunnan Province. This has resulted in establishing trade links and the importation of Chinese Hmong costumes into Australia.

These bright, mass-produced costumes, decorated with machine-produced embroidery, are increasingly used as everyday dress by young women from villages in Yunnan Province. In Australia, they have become popular as festive outfits for Hmong teenage girls. Every year, prior to the New Year celebrations, large numbers of these costumes are imported from China and frequently further embellished in Australia with additional beads, coins, lace, small bells and other decorative ornaments. In this way China, the Hmong's ancient homeland, has also been involved in the process of negotiating the new visual identity of the Australian Hmong.

The recognition of China as the ancestral home of the Hmong has further implications than the import of contemporary, mass-produced Hmong costumes. This is the place of the Hmongs' origins, with their ancient, mythical homeland believed to be situated somewhere on the northern plains of China, perhaps even in southern Siberia or on the steppes of Mongolia (Savina 1930). From there, several thousands of years ago, the Hmong believe that their ancestors started to migrate southwards. Re-establishing the connections with China through the importation of costumes creates an important new link with the country of their ancestors. ${ }^{7}$

There is no doubt that the contemporary costumes of Australian Hmong are extremely dynamic, continually changing creations, which provide tangible evidence of the group constructing a new identity and the growing significance of its international links. Although many of the Australian Hmong may not be consciously aware of this process, the costumes which they create and wear transform this non-verbal medium into a profound visual statement.

\section{The Funeral Garment}

In this very dynamic situation, there is just one type of Hmong garment in Australia which, so far, has resisted all major changes 
and retains its original form, as known in Laos. This is the funeral jacket, the powerful symbolism of which means that its materials and designs cannot be altered without negative repercussions on the whole community.

Therefore, although other Hmong costumes nowadays are made of synthetic fibres, the funeral robe and its embroidered squares of fabric are always made of organic materials such as cotton, which disintegrate faster, thus allowing the soul of the deceased a smooth passage to the other world. Metal parts, such as buttons, pins or metallic thread, are never included in the funeral robes, because the slow process of their disintegration would delay reincarnation (see also Tapp 1989).

Not only the materials, but also the designs of funeral clothes remain unchanged. The small geometric designs executed in patchwork and banding appliqué symbolise a person's possessions such as land, house and animals, and permit the deceased to take this wealth to the other world.

Many of the funeral jackets are sent to Australia by Hmong relatives living overseas - usually these are daughters and daughters-in-law who, in this way, wish to assure parents of their loyalty, care and respect. The funeral robes are given to the person during his or her life. By the age of 50, every member of the Hmong community usually has at least one set of funeral clothing, and quite commonly three or four. ${ }^{8}$

A very important part of the funeral costume is the shoes, which help the deceased to traverse the dangerous terrain on the return way to the village of ancestors. To ensure a safe passage, one has to wear a pair of special shoes, which are buried in the coffin. Traditionally, the shoes were made of hemp but nowadays the more easily available cotton fabric is used. In Australia there is only one person who makes 'death shoes' - an elderly Hmong man who lives in Sydney and cannot keep up with the demand.

In most cases therefore, the funeral shoes used by north Queensland Hmong are imported from Thailand or Laos ( $\mathrm{Mr}$ Doua Yang, Innisfail, personal communication, 2002). 


\section{Conclusions}

Although Hmong costume has almost entirely lost its practical function as a garment in Australia, it still continues to be an important expression of the group's changing identity. On festive occasions, the costumes remain the most visible manifestation of Hmong culture. This analysis of Hmong costumes also provides an interesting example of how aesthetics shift with new social positioning.

In Laos the process of costume-making and the associated transmission of skills used to bind generations of Hmong women together. In contemporary Australia, Hmong costumes still function in this way, but it is not the process of their manufacture but rather their circulation as gifts which binds and integrates Hmong family members together at a global level.

In a recent examination of theoretical models of cultural globalisation and forthcoming trends, Diana Crane has argued that in recent decades the concept of an homogenised global culture, corresponding to McLuhan's 'global village', has started to lose its significance, and is being replaced by a trend which recognises cultural globalisation as 'a complex and diverse phenomenon consisting of global cultures, originating from many different nations and regions' (Crane 2002: 1). In one such model, originally articulated by Appadurai (1990), cultural globalisation corresponds to a network with no clearly defined centre or periphery, where cultural influences move in many different directions and regional centres increase in importance as producers and markets. Although Crane bases her investigation mainly on an analysis of mass media, the examination of Australian Hmong costumes provides strong support for this model of globalisation, understood as a dynamic network of cultural flows.

The process of transformation of the traditional Hmong costume which I have presented here is based on research which was conducted only among one group of the Hmong diaspora in Australia. It would be interesting to find out whether certain aspects of this process may be relevant to groups of Hmong migrants living in other parts of the world. I would expect that 
changes similar to the Australian ones may be occurring in smaller Hmong communities, in countries such as Canada or French Guyana. In countries with more numerous and cohesive groups of Hmong, such as the United States, it may be more important to maintain the proper form of the costume, in order to express the exact lineage and origins of a person. There is no doubt, however, that increased contacts between various groups of Hmong people living in several parts of the world will continue to stimulate the exchange of costumes and dress accessories as well as relevant materials and accompanying ideas. Will this process finally lead to the creation of just one, pan-Hmong costume worn by the whole Hmong diaspora? Or will it perhaps result in the development of distinctive national costumes, different for each country, so that we would be faced with a Canadian Hmong costume or an Australian Hmong costume? In another scenario, we may find perhaps hundreds of individual, diverse creations, inspired by what used to be the traditional Hmong costume of their homeland.

Today these questions cannot be answered, as it is difficult to predict the future course of social change and what impact it will have upon the transformation of the costumes. It is certain, however, that whatever form future Hmong costume may take, it will remain an important aspect of their cultural heritage, the visual symbol of their ethnic identity and pride. 


\section{Footnotes}

${ }^{1}$ The author of this chapter would like to thank the following members of the north Queensland Hmong community for their ongoing assistance: Mr Doua Yang and Mrs Jou Yang, Mrs Poyi Thao, Mr Sai Xiong and Mrs Sua Xiong, Mr Ly Lao, Mr Sao Lee, Mr Pa Chao Thao and Mrs Mai Yang, Mrs Chi Lee, Melanie Lee, Mr Vang Yee Chang.

The fieldwork in Yunnan Province, China, was conducted in four Hmong/Miao villages, following the UNESCO-staged event 'Workshop on Transmission of the Traditional Technique of Costume-making of the Miao/Hmong people', Kunming, June 2000.

${ }^{2}$ Information provided by Hmong Queensland Association, Innisfail.

${ }^{3}$ The author prefers the term used by her informants, 'Blue Hmong', and this has been altered here by the editors, to accord with other chapters in this book. See 'Note on Orthography and Usage' in the introduction to this collection.

${ }^{4}$ For instance, the marriage of Mrs Sua Xiong and Mr Sai Xiong in 1979; and the marriage of Mrs Jou Yang and Mr Doua Yang in 1981 (Ban Vinai camp).

${ }^{5}$ Today in the collection of Queensland Museum, Brisbane.

${ }^{6}$ The cloth is in the collection of James Cook University in Townsville. During seven years spent in Ban Vinai refugee camp, Mrs Poyi Thao produced more than 100 embroidered cloths, which were sold through local handicraft shops (Mrs Poyi Thao, Cairns, personal communication, 1996).

${ }^{7}$ This reflects the views of contemporary informants, rather than actual historical fact. North Queensland Hmong, for example, refer always to a country situated in the north of China as their ancestral land. A good summary of various theories regarding the Hmong original homeland is provided by Schein (2000: 44-9).

${ }^{8}$ The severe, cold climate of the ancestral land requires that several sets of funeral garments will be placed in the coffin (Mr Ly Lao, Innisfail, personal communication, 1995). 